\title{
Peertechz
}

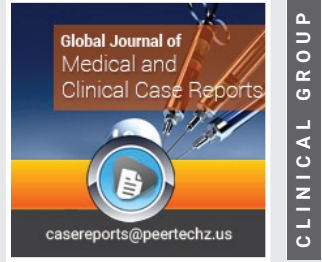

Case Report

\section{Activating dormant strongyloidiasis secondary to COVID-19 treatment}

\author{
Fahad Alkaabba1*, Holman Li $^{2}$ and Farrah Ibrahim² \\ ${ }^{1}$ Department of Medicine, University of Maryland Medical Center, Baltimore, MD, USA \\ ${ }^{2}$ Department of Medicine, University of Alabama at Birmingham, Huntsville, AL, USA
}

Received: 21 January, 2022

Accepted: 31 January, 2022

Published: 01 February, 2022

*Corresponding author: Fahad Alkaabba, Department of Medicine, University of Maryland Medical Center, Baltimore, MD, USA, E-mail:FAlKaabba@som.umaryland. edu; fahadalqabba@gmail.com

Keywords: Strongyloides stercoralis; Corticosteroids; Dexamethasone; SARS-CoV-2; Immunosuppression

Copyright License: (c) 2022 Alkaabba F, et al. This is an open-access article distributed under the terms of the Creative Commons Attribution License, which permits unrestricted use, distribution, and reproduction in any medium, provided the original author and source are credited.

https://www.peertechzpublications.com

\section{Check for updates}

\begin{abstract}
The SARS-CoV-2 pandemic has grown into a major global concern with huge efforts to combat the spread. Exaggerated inflammatory response plays a major role in which was the rationale to use corticosteroids to treat patients. However, multiple studies showed an association between opportunistic and bacterial infections with corticosteroid therapy. We report a case of a 76 year old patient diagnosed with COVID-19 treated with 10 days Dexamethasone and Remdesivir who presented with abdominal symptoms with eosinophilia. Biopsy and stool studies revealed Strongyloides stercoralis larvae. The patient was treated with 2 doses of Ivermectin with significant clinical resolution. Clinician should have high clinical suspicion for Strongloydiasis in patients who have lived or visited endemic areas and for patients with unexplained eosinophilia. Prompt treatment with Ivermectin is crucial for confirmed cases and high risk cases where obtaining a diagnosis is unfeasible.
\end{abstract}

\section{Introduction}

The SARS-CoV-2 pandemic has grown into a major global concern with huge efforts to combat the spread [1]. Exaggerated inflammatory response plays a major role in alveolar destruction that happens with severe coronavirus infection (COVID-19) as shown by many studies [2]. This finding was the reason for using corticosteroids in addition to oxygen supply as a therapy for respiratory failure in critically ill patients [3]. One randomized clinical trial, the RECOVERY trial, affirmed the survival benefits of using steroids [4]. The study showed evidence that a 10-day course of dexamethasone once daily for 10 days reduces 28-day mortality in hospitalized patients with COVID-19 on oxygen supply. Another approach to treatment was the use of antiviral therapy. Remdesivir was approved by the Food and Drug Administration (FDA) as it has shown activity against SARS-CoV-2 in vitro [5]. Multiple clinical trials were conducted to assess remdesivir efficacy with variable results [6].

Upon review of literature, multiple studies showed a higher risk of opportunistic and bacterial infection with corticosteroid therapy [7]. When using this drug, continuous clinical monitoring is recommended, as secondary infections might arise [8].

The soil-transmitted nematode Strongyloides stercoralis is the pathogen that causes Strongyloidiasis, The global prevalence is estimated to be $30-100$ million. The nematode is endemic in tropical and subtropical regions [9-20].

Reports of activation or exacerbation of S. stercoralis infection in COVID-19 patients treated with either dexamethasone or Remdesivir are few $[10,19,20]$. Here, we present a case of a 76 year old male with COVID-19 and reactivation of Strongyloides infection.

\section{Case presentation}

This is a 76 year-old male who presented with a chief complaint of abdominal pain. He has past medical history significant for Chronic Obstructive Pulmonary Disease (COPD) on home oxygen, Chronic Kidney Disease (CKD), Coronary Artery Disease (CAD), hypertension, and a recent COVID-19 infection two weeks prior to admission. The patient localized 
the abdominal pain mainly in the epigastric area and reported associated anorexia, nausea, vomiting, and diarrhea. Moreover, he noted a weight loss of $17 \mathrm{~kg}$ within the last 8 months. There were no reports of anorexia, diarrhea, flatulence, constipation, hematemesis, melena, hematochezia, fever, sweats, or chills. During his last admission for COVID-19 infection, the patient was put on $2 \mathrm{~L}$ nasal cannula oxygen. He required no respiratory support. Additionally, he received a course of 6mg Dexamethasone, and Remdesivir with a loading dose of 200mg intravenously then 100mg maintenance dose for 5 days, and convalescent plasma therapy. Of note, the patient had a colonoscopy 10 years ago and esophagogastroduodenoscopy 7 years ago, both of which were unremarkable. On presentation, the patient's vital signs were notable for oxygen saturation of $97 \%$ on ambient air, temperature of 98.2 degrees, blood pressure of $110 / 80 \mathrm{mmHg}$, heart rate of 78 beats/minutes and respiratory rate of 14 breaths/minute. On physical examination, the patient appeared cachectic. He was alert and oriented to person, place, time, and situation. His sclerae were anicteric. Auscultation of the heart showed regular rate and rhythm with no murmurs, and auscultation of the lungs showed equal air entry with no added sounds. Examination of the abdomen revealed normoactive bowel sounds with epigastric tenderness without organomegaly. Neurological examination was nonfocal. Initial laboratory workup was significant for hyponatremia of $122 \mathrm{mEq} / \mathrm{L}$, leukocytosis with eosinophilia, and urinalysis consistent with urinary tract infection with positive leukocyte esterase and bacteria. Urine studies show high urine sodium, low serum osmolality, and high urine osmolality, consistent with SIADH. CT abdomen showed focal colonic wall thickening involving the cecum and right hemicolon. During his hospital stay, and as part of hyponatremia protocol, he was placed on fluid restriction with minimal improvement. He was started on 15mg tolvaptan orally afterward, which improved his sodium. Given the inconclusive CT findings, the Gastroenterology team was consulted for further evaluation. Patient was taken to the endoscopy lab. Colonoscopy was attempted but was limited due to poor bowel prep. Upper endoscopy showed Los Angeles (LA) grade D erosive esophagitis. Biopsies were obtained for pathological examination. Pathology was significant for acute inflammation and necrosis. Duodenitis was also noted with parasitic infection. Due to this finding, a stool sample with concentrated ova and parasite wet mount revealed Strongyloides stercoralis larvae. In light of these findings, a diagnosis of Strongloydiasis was made. Further history was obtained from the patient, he did not report residing or visiting an endemic area recently. The patient also denied a family history of strongloydiasis infections. Patient was maintained on sucralfate and was given two doses of $0.2 / \mathrm{kg}$ Ivermectin orally. The patient reported a resolution of nausea, diarrhea, and abdominal pain within several days. His appetite improved marginally. Patient was then discharged from the hospital with close outpatient follow-up.

\section{Discussion}

Upon review of literature, reports of Strongyloides exacerbation with COVID-19 are scarce. However, based on clinical experience with the use of steroids to treat other diseases; exacerbation of S. stercoralis infestation can occur [11]. Different therapeutic approaches have been developed for COVID-19, with the ongoing debate regarding their efficacy. The findings of the RECOVERY trial have been encouraging [4]. However, applying these results is limited in certain settings, especially in low-income African countries [12]. One of the concerns raised by the authors was the risk of reactivating or worsening dormant infections like tuberculosis or strongyloidiasis.

Strongyloidiasis is caused by infection by the helminth Strongyloides stercoralis. The filariform larvae usually reside in soil or other sources contaminated by human feces and enter the body through the skin. The larvae migrate to the lungs where they travel up the tracheobronchial tree and get swallowed. It matures in the intestine and deposits eggs into the mucosa. Rhabditiform larvae hatch and are excreted in the stool to restart the life cycle. Rhabditiform larvae may also become filariform larvae and travel to the lungs for autoinfection. Adult worms may live up to 5 years without causing symptoms [9].

Strongyloidiasis can present with a spectrum of symptoms, ranging from mild to severe [9]. With immunosuppression, it can present with a disseminated infection or high fatality rates (up to $70-100 \%$ ) [13]. This disseminated state is severe and can result in the colonization of parasites to body areas that it normally does not reach. These include organs like the liver, heart, brain and urinary tract [14]. Given these high fatality rates, high clinical suspicion should be implemented to screen for patients with high risk for infection reactivation and to start empiric treatment if diagnostic tools are unavailable [15]. The case presented here did not raise suspicion for increased risk of strongyloidiasis; this suggests the diagnosis was possibly associated with the use of high-dose corticosteroids for COVID-19. Fortunately, the patient in our case did not develop a disseminated infection which can be possibly attributed to early detection and timely treatment. Disseminated infection, also termed hyperinfection, is defined by finding the parasite in organs outside its natural life cycle, meaning organs other the skin, GI tract, or lungs [16]. On further review of our patient history, we also note an 8-month history of cachexia which implies the patient might have been having an active infection due to strongyloidiasis during that period.

The risk of disseminated infections has been gaining recognition. A recently published paper proposed a dedicated strategy for epidemiological risk stratification to prevent disseminated Strongyloides infection for COVID-19 patients on high-dose steroids therapy [16]. Based on this strategy, a presumptive ivermectin treatment can be offered to patients at high risk who initiate or are candidates for steroids in both outpatient and inpatient settings.

The efficacy of single dose Ivermectin has been wellestablished for patients with confirmed uncomplicated infection [17]. A longer course of treatment can be offered for patients with disseminated infections [18]. The patient in our case was treated with two doses of Ivermectin due to the underlying immunosuppression with corticosteroids therapy. 


\section{Conclusion}

In conclusion, we report a case of confirmed strongyloidiasis in a COVID-19 patient treated with high-dose steroids. High clinical suspicion should be implemented especially for patients who have lived or visited endemic areas. Moreover, it is recommended to consider strongyloidiasis in patients with unexplained eosinophilia. Prompt treatment with Ivermectin should be considered for confirmed cases or for high risk cases where obtaining a diagnosis is unfeasible.

\section{Data availability statement}

All data underlying the results are available as part of the article and no additional source data are required.

\section{References}

1. Rothan HA, Byrareddy SN (2020) The epidemiology and pathogenesis of coronavirus disease (COVID-19) outbreak. J Autoimmun 109: 102433.Link: https://bit.ly/3GhdXIk

2. Zhang C, Wu Z, Li JW, Zhao H, Wang GQ (2020) Cytokine release syndrome in severe COVID-19: interleukin-6 receptor antagonist tocilizumab may be the key to reduce mortality. Int J Antimicrob Agents 55: 105954. Link: https://bit.ly/3GieP96

3. Veronese N, Demurtas J, Yang L, Tonelli R, Barbagallo M, et al (2020) Use of corticosteroids in Coronavirus disease 2019 pneumonia: A systematic review of the literature. Front Med (Lausanne) 7. Link: https://bit.ly/35EInkV

4. Horby P, Lim WS, Emberson JR, Mafham M, Bell JL, et al. (2021) Dexamethasone in hospitalized patients with covid-19. N Engl J Med 384: 693-704. Link: https://bit.ly/3L1vXne

5. Wang M, Cao R, Zhang L, Yang X, Liu J, et al (2020) Remdesivir and chloroquine effectively inhibit the recently emerged novel coronavirus (2019-nCoV) in vitro. Cell Res 30: 269-271. Link: https://bit.ly/3J9IZOv

6. Frost $M T$, Jimenez-Solem $E$, Ankarfeldt $M Z$, Nyeland $M E$, Andreasen $A H$, et al. (2020) The Adaptive COVID-19 Treatment Trial-1 (ACTT-1) in a real-world population: a comparative observational study. Crit Care 24: 677. Link: https://bit.ly/3s6qBOZ

7. Obata R, Maeda T, Rizk D, Kuno $T$ (2021) Increased secondary infection in COVID-19 patients treated with steroids in New York city. Jpn J Infect Dis 74: 307-315. Link: https://bit.ly/3gc4eC2

8. Klein NC, Go CH-U, Cunha BA (2001) Infections associated with steroid use. Infect Dis Clin North Am 15: 423-432. Link: https://bit.ly/3A0479h
9. Greaves D, Coggle S, Pollard C, Aliyu SH, Moore EM (2013) Strongyloides stercoralis infection. BMJ 347: f4610. Link: https://bit.ly/347AyUq

10. Mafort TT, Reis LVT, Faria LF, Pinto BM, Silva RV, et al. (2017) Alveolar hemorrhage secondary to infection by strongyloides stercoralis in immunosuppressed patient-case report. Am J Respir Crit Care Med 195: A5586. Link: https://bit.ly/34bSvRA

11. Buonfrate D, Requena-Mendez A, Angheben A, Muñoz J, Gobbi F, et al. (2013) Severe strongyloidiasis: a systematic review of case reports. BMC Infect Dis 13: 78. Link: https://bit.ly/3APQvKF

12. Brotherton H, Usuf E, Nadjm B, Forrest K, Bojang K, et al. (2020) Dexamethasone for COVID-19: data needed from randomised clinical trials in Africa. Lancet Glob Health 8: e1125-e1126. Link: https://bit.ly/3oh9VDs

13. Mejia R, Nutman TB (2012) Screening, prevention, and treatment for hyperinfection syndrome and disseminated infections caused by Strongyloides stercoralis. Curr Opin Infect Dis 25: 458-463. Link: https://bit.ly/3APQhTP

14. Kassalik M, Mönkemüller K (2011) Strongyloides stercoralis hyperinfection syndrome and disseminated disease. Gastroenterol Hepatol (N Y) 7: 766-768. Link: https://bit.ly/3ITF91x

15. Requena-Méndez A, Buonfrate D, Gomez-Junyent J, Zammarchi L, Bisoffi Z, et al. (2017) Evidence-based guidelines for screening and management of strongyloidiasis in non-endemic countries. Am J Trop Med Hyg 97: 645-652. Link: https://bit.ly/3gdKs9t

16. Stauffer WM, Alpern JD, Walker PF (2020) COVID-19 and dexamethasone: A potential strategy to avoid steroid-related Strongyloides hyperinfection: A potential strategy to avoid steroid-related Strongyloides hyperinfection. JAMA 324: 623-624. Link: https://bit.ly/3Gbzyvq

17. Buonfrate D, Salas-Coronas J, Muñoz J, Maruri BT, Rodari P, et al. (2019) Multiple-dose versus single-dose ivermectin for Strongyloides stercoralis infection (Strong Treat 1 to 4): a multicentre, open-label, phase 3, randomised controlled superiority trial. Lancet Infect Dis 19: 1181-1190. Link: https://bit.ly/3IPU4n6

18. CDC-Centers for Disease Control (2010) Prevention. CDC - Strongyloides resources for health professionals.

19. Marchese V, Crosato V, Gulletta M, Castelnuovo F, Cristini G, et al. (2021) Strongyloides infection manifested during immunosuppressive therapy for SARS-CoV-2 pneumonia. Infection 49: 539-542. Link: https://bit.ly/3ulTKsp

20. Lier AJ, Tuan JJ, Davis MW, Paulson N, McManus D, et al. (2020) Case report: Disseminated strongyloidiasis in a patient with COVID-19. Am J Trop Med Hyg 103: 1590-1592. Link: https://bit.ly/3of2Mn1

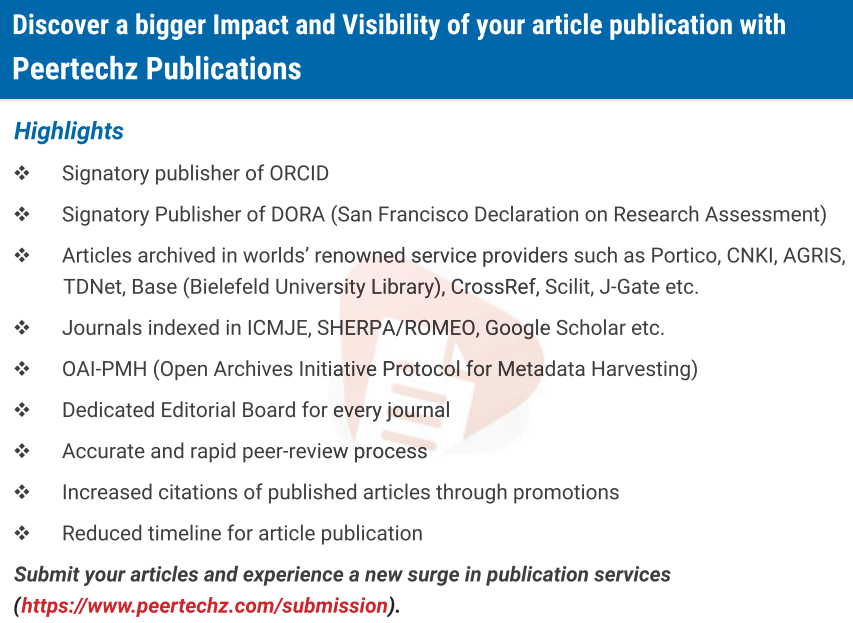

